\title{
Are some more equal than others? Challenging the basis for prisoners' exclusion from Medicare
}

\section{A mixed funding approach can help meet the urgent requirement for a level of health care in prison commensurate with need and equivalent to community standards}

\footnotetext{
onsistent with global literature, ${ }^{1}$ prisoners in Australia experience profound health

disparities relative to those who have not
} been incarcerated, with a disproportionate burden of mental illness, chronic and communicable diseases. ${ }^{2,3}$ Many prisoners have complex histories of disadvantage encompassing family violence, unstable housing, limited education, unemployment and economic adversity. Risky health-related behaviours including smoking, illicit drug use, harmful alcohol consumption and unsafe sexual practices are common in incarcerated populations. ${ }^{2}$

Correctional settings are uniquely placed to detect health problems, initiate care and promote health in a way that is unlikely to occur in the community, with important public health implications for the communities to which prisoners return. ${ }^{4}$ It is paradoxical, therefore, that prisoners are excluded from Australia's universal health care scheme Medicare - while incarcerated. Instead, health care for prisoners is transferred to state and territory government departments for the duration of their incarceration.

Some of Australia's peak health and medical advocacy groups have criticised this exclusion, arguing that it transgresses human rights, results in suboptimal care, and perpetuates the cycle of ill health and disadvantage. ${ }^{5,6}$ Although these groups have called for reform to the legislation that underpins this exclusion, a way forward has not been clearly articulated. In this article, we outline the legal basis for prisoners' exclusion from Medicare, articulate key arguments for reform and offer some pragmatic next steps, informed by an understanding of the legislation and an appreciation that wholesale replacement of prison health services with Medicare is neither workable nor desirable.

\section{The evolution of Medicare - the basis for prisoners" exclusion}

Australia's universal health care system, originally called Medibank, was introduced in 1975 by the Whitlam Labor government in response to widespread dissatisfaction and inequities caused by the previous

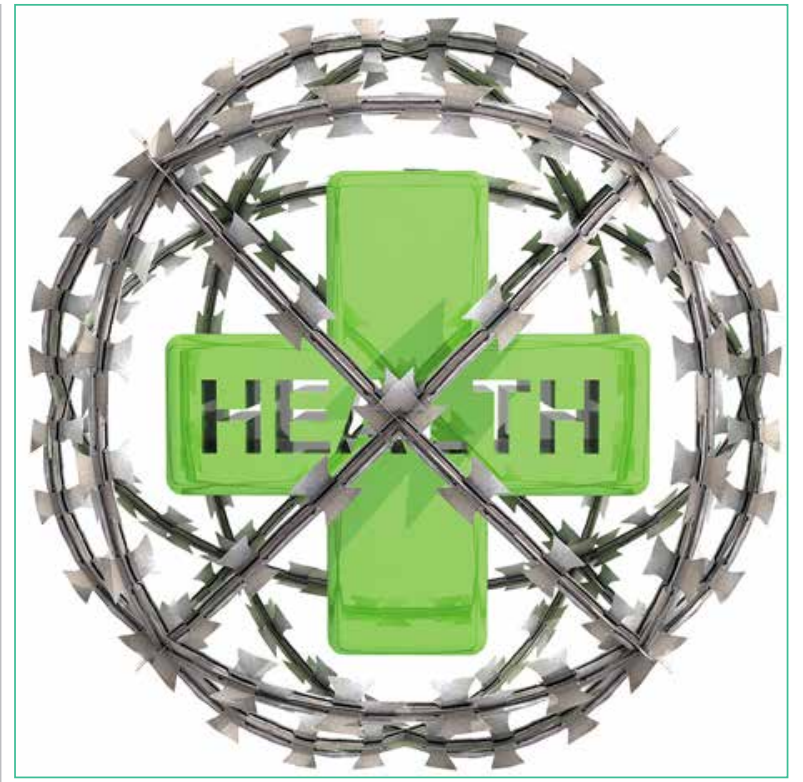

voluntary health insurance scheme. ${ }^{7}$ Following numerous reviews and alterations, the system was reincarnated in 1984 as the Medicare Benefits Scheme (MBS). ${ }^{8}$ The Pharmaceutical Benefits Scheme predates Medicare, with some benefits first made available in 1948. Today, these two taxpayer-funded schemes, collectively known as Medicare, are centrally administered under the Health Insurance Act 1973 (Cwlth).

Until the introduction of Medicare in the mid 1970s, regulation of health was not a federal government

Tessa M Plueckhahn BA(Hons), JD'

Stuart A Kinner

$\mathrm{PhD}^{2.3}$

Georgina Sutherland BAppSc(Hons), PhD

Tony G Butle

$\mathrm{PhD}$

1 The Kirby Institute University of New South Wales, Sydney, NSW 2 Griffith Criminology Institute and Menzies Health Institute Queensland, Griffith University, Brisbane, QLD.

3 Melbourne School of

Population and Global Health, University of Melbourne, Melbourne, VIC

georgina.sutherland@ unimelb.edu.au

doi: 10.5694/mjal5.00588 power, and an amendment to the Constitution was required to make the federal system possible. The first years of constructing and implementing Medicare revealed the enormous economic burden that it would be for the government. In 1976, a review committee was established to "trim the fat", and the resulting legislative amendments were aimed at carving out situations in which Medicare subsidies would not apply if there was another source of funding. ${ }^{9}$

An amendment in 1976 to the Health Insurance Act s 19(2) - states that where health services are being provided by, on behalf of, or under an arrangement with any government entity (whether federal, state or territory), Medicare will not be available unless the Minister for Health or his/her delegate grants an exemption to this exclusion. As state-funded entities, prisons fall under this domain and thus, the legislation operates on the assumption that prisoners are excluded from Medicare because the state or territory in which they are incarcerated provides equivalent services. 
It also presumes that allowing access to Medicare for prisoners, who are provided with care at the expense of state or territory governments, would either constitute double dipping, or allow states and territories access to federal funds for an area that should be their economic burden to bear.

\section{Is equivalence a reasonable assumption?}

Health care in Australian custodial settings is guided by the concept of community equivalence, as outlined in numerous national and international frameworks. ${ }^{5,10}$ In principle, this means prisoners are entitled to receive the same level of access and quality of health care as the general population. In reality, however, persistent underinvestment in health services means that prisoners may miss out on certain treatments and medications. ${ }^{11}$ While the complexity of governance and funding arrangements in prisons means that it is often difficult to determine whether equivalence of care has been achieved, ${ }^{2}$ there are a number of key areas in which states and territories are failing to meet their obligations. Below, we consider two examples whereby the lack of access to Medicare affects prisoners' health.

\section{"prisons have substantially underinvested in health care, often because services are too expensive to deliver without access to Medicare rebates"}

The Medicare Health Assessment for Aboriginal and Torres Strait Islander People (MBS item 715) is designed to target the ongoing health needs of Indigenous people who experience earlier onset and more severe progression of chronic illnesses than nonIndigenous Australians. Prisoners' effective exclusion from Medicare means that neither prisoner health services nor community organisations that provide health services to Aboriginal and Torres Strait Islander people in prison can claim Medicare billing for this item. We know of no equivalent, culturally acceptable health assessment delivered in prisons in Australia, despite a well recognised need for Aboriginal-specific justice health services. ${ }^{12}$

Despite prisoners having some of the highest rates of mental illness of any population group, there is increasing evidence that prisons do not have the resources to address the extent of need. In the community, Medicare rebates are available for up to 10 allied mental health services in any one calendar year, with additional rebates available for group-based therapies. In prison, limited mental health resources are typically directed to those with the most severe mental health disorders and psychotropic medications are the mainstay of treatment for the majority. ${ }^{2}$ Unlike Medicare-subsidised schemes in the community, most prisoners have limited access to ongoing counselling and other individual therapeutic approaches, particularly for the treatment of common mental disorders, such as depression.

\section{Exemptions to exclusion from Medicare - the equity argument}

Parliamentary documents show that the Health Minister's power to waive the Medicare exclusion was explicitly included in s 19(2) of the Health Insurance Act so that governments could make amendments if the exclusion was deemed to cause disadvantage..$^{9}$ In practice, the Commonwealth has been willing to grant exemptions in cases of clear and demonstrated need. Two main groups of exemptions exist.

The first applies to Commonwealth-funded Aboriginal Community Controlled Health Services (ACCHSs). While the Act states that Medicare entitlements do not apply to services already funded by the Commonwealth, an exemption was granted in recognition of the gap in services between ACCHSs and mainstream primary care. The Inala Indigenous Health Service in South East Queensland also has an exemption. This service is a state-based primary care practice funded by Queensland Health and was granted an exemption in 2006, allowing services to be rebated through Medicare. ${ }^{13}$

Similarly, in 2006, the Council of Australian Governments (COAG) implemented the Improving Access to Primary Care in Rural and Remote Areas (s 19[2] Exemptions) Initiative. The COAG exemptions are open to eligible state funded health organisations that operate in areas with small populations $(<7000)$ with identified health workforce shortages. Recognising that state-funded facilities in small rural and remote towns provide primary care, the COAG exemption was granted to permit these organisations to bill Medicare for non-admitted, non-referred services. $^{14}$

These precedents demonstrate the willingness of Commonwealth governments to permit access to Medicare if the ability of a health service to adequately care for the needs of a community was curtailed by the exclusion; a situation that clearly exists in prisons. The current exemptions all share a common theme: an expressed intention to ensure that all Australians have access to appropriate and quality health care, regardless of their circumstances. All of the current exemptions were granted in the last years of the Howard Coalition government under the then Minister for Health and Ageing, Tony Abbott.

\section{Reforming funding for prisoner health care -} a way forward

Legal action on the subject of prisoner health care has at times been successful, and has prompted meaningful change, such as access to condoms in 
prisons (Prisoners A-Xx Inclusive v State of New South Wales [1995] NSWSC 109). It has also been used in individual cases, such as Allan Petit $v$ State of New South Wales [2012] NSWDC 105, where the failure of a New South Wales prison authority to inform a prisoner that he tested positive for hepatitis $\mathrm{C}$ after several blood tests was deemed to have deprived him of the opportunity to receive treatment and potentially prevent further transmission. Legal action in Castles $v$ Secretary of the Department of Justice [2010] VSC 181 was successful in granting a female prisoner serving a term in a minimum security facility leave to access in-vitro fertilisation before she reached the age limit in Victoria. However, in relation to prisoners' exclusion from Medicare, the issues are more complex. The legislation is clear: state and territory authorities are responsible for prisoners. Legal action against the responsible state government would not resolve the issue when the problem lies with federal legislation.

The Health Minister has the power, under the Health Insurance Act, to grant an exemption that would end prisoners' exclusion from Medicare, paving the way for rebates to be claimed for prison-based health care services in certain circumstances. In an arrangement similar to that enjoyed by other state-based services that operate under s 19(2) exemptions (eg, Inala Indigenous Health Service), this would allow prisons to retain their existing health service delivery model but to enhance service delivery through access to certain Medicare items. Costs incurred by Medicare would be minimal. As an example, we estimate the cost of delivering the Indigenous-specific health assessment to every Indigenous prisoner in Australia in any one year would be less than $0.01 \%$ of the annual
$\$ 20$ billion Medicare budget (based on the current rebate of \$212.25). Given that the focus of the health assessment is on disease prevention in Indigenous populations, combined with evidence that uptake in the community is poor among those most at risk, ${ }_{15}^{15}$ delivering this service in prisons has strong costeffectiveness credentials. We are not aware of publicly available data comparing per capita expenditure on prison-based and community health care, although such information would inform the equivalence debate.

Cost sharing between the states and territories and the Commonwealth to achieve equity in prisoner health care is not new and has been debated by public health policy advocates in Australia for over a decade. What has emerged in the interim is evidence that prisons have substantially underinvested in health care, often because services are too expensive to deliver without access to Medicare rebates. Our proposal for a mixed funding model aligns with current government policy, whereby scarce health resources can be directed to where they will be most effective in improving the health of all Australians.

Acknowledgements: This study was partially funded by a National Health and Medical Research Council (NHMRC) Indigenous offender health capacity building grant "From Broome to Berrima: Building Australia-wide research capacity in Indigenous offender health and health care delivery" (533546). Stuart Kinner holds an NHMRC Senior Research Fellowship (1078168).

Competing interests: No relevant disclosures.

Provenance: Not commissioned; externally peer reviewed.

References are available online at www.mja.com.au.

(c) 2015 AMPCo Pty Ltd. Produced with Elsevier B.V. All rights reserved. 
1 Fazel S, Baillargeon J. The health of prisoners. Lancet 2011; 377: 956-965.

2 Australian Institute of Health and Welfare. The health of Australia's prisoners 2012. Canberra: AlHW, 2013. (AlHW Cat. No. PHE 170.) http://www.aihw.gov.au/WorkArea/ DownloadAsset.aspx?id=60129543945 (accessed Sep 2015).

3 Butler T, Andrews G, Allnutt S, et al. Mental disorders in Australian prisoners: A comparison with a community sample. Aust N Z J Psychiatry 2006; 40: 272-276.

4 Lines R. From equivalence of standards to equivalence of objectives: The entitlement of prisoners to health care standards higher than those outside prisons. Int J Prison Health 2006; 2: 269-280.

5 Australian Medical Association. Position statement on health and the criminal justice system 2012. https://ama.com.au/ position-statement/health-and-criminal-justice-system-2012 (accessed Sep 2015).

6 Public Health Association of Australia. Prisoner health policy. https://www.phaa.net.au/documents/item/239 (accessed Sep 2015).

7 Parliament of Australia. Hansard. House of Representatives, 29 November 1973 (Bill Hayden).

8 Biggs A. Medicare - background brief. 29 Oct 2004. Canberra: Parliament of Australia. http://www.aph.gov. au/About_Parliament/Parliamentary_Departments/ Parliamentary_Library/Publications_Archive/archive/ medicare (accessed Sep 2105).

9 Parliament of Australia. Hansard. House of Representatives, 20 May 1976 (Ralph Hunt).

10 Møller L, Stöver H, Jürgens R, et al, editors. Health in prisons: a WHO guide to the essentials in prison health. Copenhagen: World Health Organization Europe, 2007. http://www.euro. who.int/_data/assets/pdf_file/0009/99018/E90174.pdf (accessed Sep 2015).

1 Kinner SA, Streitberg L, Butler T, et al. Prisoner and ex-prisoner health. Improving access to primary care. Aust Fam Physician 2012; 41: 535-537.

12 Indig D, McEntyre E, Page J, Ross B. 2009 NSW inmate health survey: Aboriginal health report. Sydney: Justice Health, 2010. http://www.justicehealth.nsw.gov.au/publications/inmatehealth-survey-aboriginal-health-report.pdf (accessed Sep 2015).

13 Hayman NE, White NE, Spurling GK. Improving Indigenous patients' access to mainstream health services: the Inala experience. Med J Aust 2009; 190: 604-606. https://www. mja.com.au/journal/2009/190/10/improving-indigenouspatients-access-mainstream-health-services-inalaexperience

14 Queensland Government, Department of Health and Ageing. Medicare billing for primary care in small rural hospitals: COAG section 19(2) exemption for non-admitted services April 2007. Queensland statewide guidelines for implementation. http:// www.rdaq.com.au/Portals/RDAQ/Documents/Reports/ Coag19fowebsite.pdf (accessed Sep 2015).

15 Bailie J, Schierhout GH, Kelaher MA, et al. Follow-up of Indigenous-specific health assessments - a socioecological analysis. Med J Aust 2014; 200: 653-657. https://www.mja.com. au/journal/2014/200/11/follow-indigenous-specific-healthassessments-socioecological-analysis 